\title{
Marie-Madeleine Fragonard, Pierre-E. Leroy, a cura di, Les Pithou. Les lettres et la paix du royaume, Actes du colloque de Troyes (13-15 avril 1998)
}

\section{Filippo Fonio}

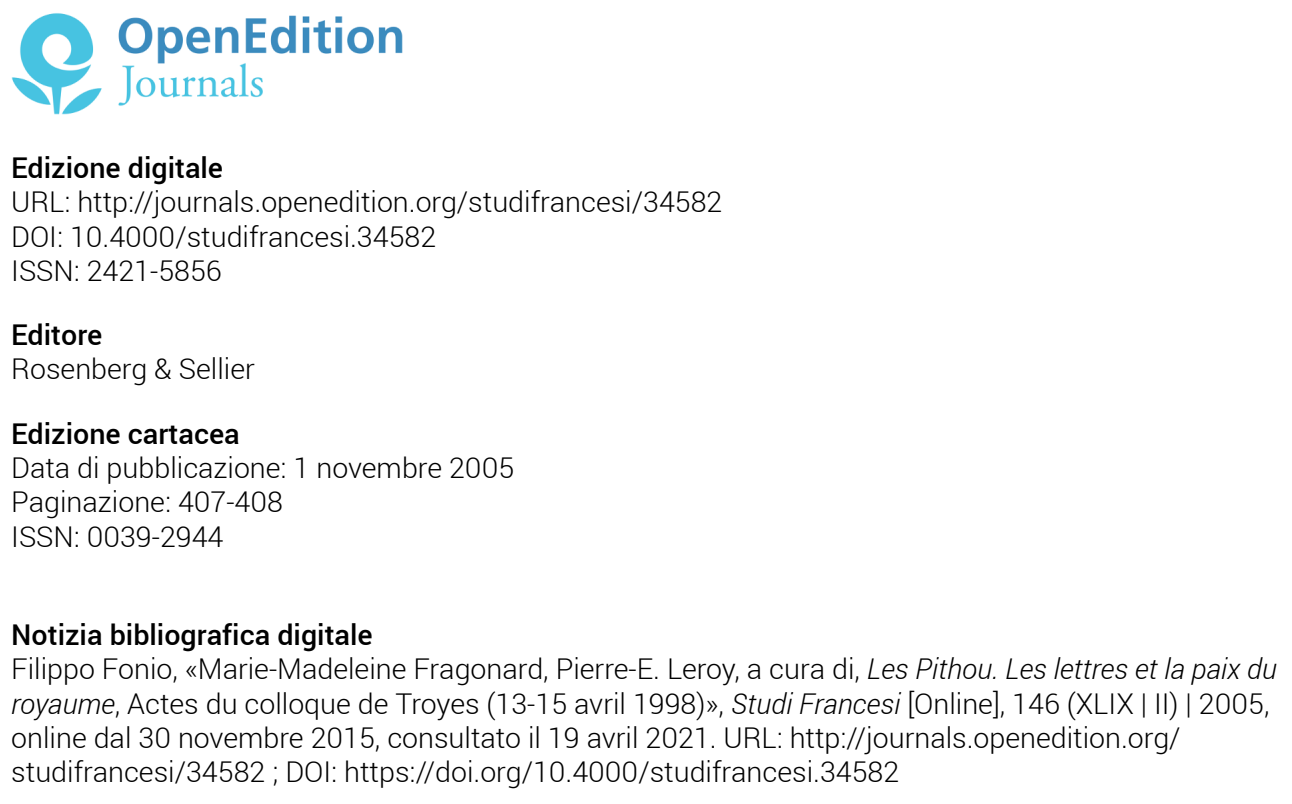

Questo documento è stato generato automaticamente il 19 avril 2021.

\section{(ब) $\odot \Theta \Theta$}

Studi Francesi è distribuita con Licenza Creative Commons Attribuzione - Non commerciale - Non opere derivate 4.0 Internazionale. 


\title{
Marie-Madeleine Fragonard, Pierre- E. Leroy, a cura di, Les Pithou. Les lettres et la paix du royaume, Actes du colloque de Troyes (13-15 avril 1998)
}

\author{
Filippo Fonio
}

\section{NOTIZIA}

MARIE-MADELEINE FRAGONARD, PIERRE-E. LEROY, a cura di (avec la collaboration d'Anne Ravit), Les Pithou. Les lettres et la paix du royaume, Actes du colloque de Troyes (13-15 avril 1998), Paris, Honoré Champion ("Colloques, congrès et conférences sur la Renaissance», 38), 2003, pp. 493.

1 Il colloquio del quale il volume raccoglie gli Atti - integrati da contributi presentati originariamente in altre sedi e aggiornati per l'occasione - ha avuto luogo nel quattrocentesimo anniversario dell'editto di Nantes. Notevole è l'importanza della famiglia Pithou per la città di Troyes come per la Champagne, in special modo per $\mathrm{i}$ contributi alla cultura negli anni delle Guerre di Religione, il numero di letterati fra i suoi membri, lo stretto legame con l'editoria della regione, la promozione di un collège a Troyes. Alcuni dei Pithou sceglieranno la strada della conversione al cattolicesimo romano, facendosi promotori della via gallicana, mentre altri non rinnegheranno la fede ugonotta nel corso delle vicissitudini di quel periodo turbolento della storia di Francia, e pur in una città ligueuse come Troyes. I due interventi introduttivi (PIERRE-E. LEROY, Depuis l'Édit de Nantes: la distance et l'oubli?, pp. 9-16; PIERRE CHEVALLIER, La Ligue en Champagne, pp. 17-27) tracciano un quadro della regione nel XVI e nei primi decenni del XVII secolo.

2 La prima delle tre sezioni in cui gli interventi sono ripartiti (Troyes, les Pithou et les modes de survie) comprende contributi sulla città di Troyes, in particolare sulla storia delle 
stamperie reali e sulla sottomissione della municipalità alla monarchia (MICHEL TURQUOIS, Quelques aspects de l'imprimerie à Troyes aux XVI et XVII e siècles, pp. 31-43; JACKY PROVENCE, L'entrée de Henri IV à Troyes, pp. 45-63), nonché sul ruolo della famiglia Pithou nell'ambito della vita politica cittadina, specie per ciò che riguarda l'istruzione (JEAN MURARD, Les Pithou et l'école, pp. 65-88; AMY ENRIGHT, Peace and the politics of education. François Pithou and the Collège de Troyes, pp. 89-103). Chiudono la sezione due interventi incentrati sulle forme mediante cui il ricordo della famiglia e dei suoi membri più influenti ha potuto mantenersi vivo e trovare una certa diffusione: FRANCINE WILD, Présence et fragilité de la mémoire: la famille Pithou dans les recueils d'antan, pp. 105-119; PIERRE-FRANÇOIS BURGER, Pierre-Jean Grosley biographe de Pierre Pithou (1539-1596), pp. 121-134.

3 La seconda sezione, Réligion économie et politique, comprende altri contributi sulla situazione socio-economica della Champagne, focalizzando il discorso sulla Chiesa e la vita religiosa: SYLVAIN MICHON, Le poids économique de l'Église en Champagne méridionale au moment des Guerres de Religion. Premières hypothèses, pp. 137-152; RÉMY DUBUISSON, L'application de l'Édit de Nantes en Champagne, pp. 229-241. I restanti interventi iniziano una messa a fuoco delle personalità di spicco della famiglia Pithou in relazione al loro apporto alla République des Lettres, con particolare attenzione ai fratelli Pierre e Nicolas. Il primo è fra gli autori di una Satyre Ménippée (MARTIAL MARTIN, La contribution de Pierre Pithou à la Satyre Ménippée. L'illustration paradoxale d'une conception exigeante du talent oratoire, pp. 215-228), mentre al secondo si deve la stesura di una Histoire ecclésiastique de l'Église réformée de Troyes (PIERRE-E. LEROY, Présentation de l'édition de la Chronique de Nicolas Pithou ou Histoire ecclésiastique de l'Église de Troyes, pp. 169-180; THIERRY WANEGFFELEN, La temporisation au temps des Confessions. Le paradoxe du cas de l'Église réformée de Troyes d'après l'Histoire ecclésiastique de Nicolas Pithou, pp. 181-191; ISABELle PaLASI, Entre Humanisme et Réforme. La conception de l'histoire chez Nicolas Pithou au XVI siècle, pp. 193-214). La scomparsa di ciascuno dei due fratelli ha fra l'altro dato vita a iniziative culturali per alcuni versi assimilabili, seppure originatesi in ambienti confessionali assai distanti: ROGER ZUBER, Tombeaux pour des Pithou: frontières confessionnelles et unité religieuse (1590-1600), pp. 153-168.

4 Eccettuato un solo contributo (FRANÇOISE BIBOLET, Les Pithou et l'amour des livres, pp. 295-304), la terza e ultima sezione di cui consta il volume, Histoire et érudition, è interamente dedicata all'attività storico-erudita di Pierre Pithou e alle relazioni intrattenute con insigni letterati e giuristi dell'epoca: MYRIAM YARDENI, Pierre Pithou historien, pp. 245-254; THIERRY AMALOU, Gallicanisme et érudition historique chez les contemporains de Pierre Pithou. Le cas de Nicolas Lenfant, procureur à Meaux (1529-1610), pp. 255-293; FRANÇOIS ROUDAUT, Note sur Étienne Pasquier et Pierre Pithou, pp. 305-312; CATHERINE MAGNIEN, Pierre Pithou dans Les Lettres de Pasquier (1586 et 1619), pp. 313-326; JERÔME DELATOUR, De Pithou à Dupuy: un siècle de religion politique, pp. 327-352; MARIE-MADELEINE FRAGONARD, L'érudition entre idéal irénique et tentation polémique, pp. 353-365.

5 A chiusura del volume un indice dei nomi, preceduto da una importante serie di Annexes ad alcuni dei contributi, fra cui da segnalare è una bibliografia delle pubblicazioni di Pierre Pithou, curata da MARIE-MADELEINE FRAGONARD. 